\section{Review Article}

Korean J Transplant 2020;34:219-230

https://doi.org/10.4285/kjt.20.0040

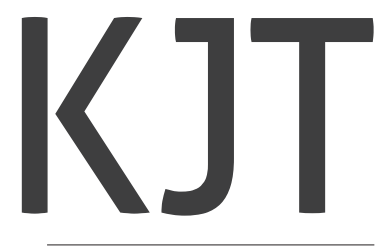

pISSN 2671-8790

elSSN 2671-8804

\title{
Causes of donation failure and improvement measures analyzed based on data from domestic deceased donors in 2019
}

\author{
Won-Hyun Cho \\ Korea Organ Donation Agency, Seoul, Korea
}

In 2019, 1,630 organs were recovered from 450 brain death donors nationwide and were transplanted into 1,612 transplant recipients. However, considering that the number of potential brain-dead linked to the Korea Organ Donation Agency (KODA) information center was 2,484 , only $18.1 \%$ of the linked brain-dead donated successfully. Of the 1,606 people who were available for family interviews, $67.0 \%$ refused to donate, so their cause analysis and countermeasures are needed. In particular, 203 reported cases died during the early period of donor evaluation, so we need a special concern on these cases. After consent, 67 cases failed to donate due to death or poor organ condition, and this raises the question of the possibility of shortening brain death management time. The average time interval from the first investigation to the completion of the second investigation (11.5 hours), until obtaining a flat electroencephalogram (5.3 hours) and conclusion of the brain death committee is 5.9 hours. Reducing unnecessary brain death management time is expected to improve the quality of organs and increase the number of organs to be recovered. Therefore, efforts to accurately identify and report potential brain death, and efforts to reduce the time spent in confirming brain death together with improving awareness of organ donation in people across the country are necessary to increase the number of deceased donors even in the current brain death management system. Implementation of donation after circulatory death for mortality case during the donor management is also urgent.

Keywords: Brain death; Donor; Donor screening; Deceased donor

\section{INTRODUCTION}

During the year 2019, there were 450 deceased donors in Korea, and 1,612 organs were donated from them. However, considering 32,990 patients waiting for a transplant at the end of 2019, the supply and demand of organs still shows a big difference. While reporting on the status of domestic deceased organ donation in 2019, we intend to identify the problems that have been revealed, and find and suggest future improvements.

\section{SUMMARY OF DOMESTIC BRAIN DEATH DONOR IN 2019}

The male to female sex ratio of 450 brain death donors in 2019 was $2: 1$, and the average age was 47.0 years (66 days to 86 years). The decrease in average age compared to the previous years is due to an increased frequency of donors in their 20s and 30s. The number of brain death donor per million population (pmp) was 8.70 (central region, 8.99; south-west region, 6.99; south-east region, 


\section{HIGHLIGHTS}

- The consent rate of families is closely related to the national consensus on life sharing, education and publicity, and government policies to save end-stage failure patients using all possible donor resources.

- The donor's will or family's intention to donate their loved one should be respected by successful organ recovering and transplantation.

$9.49 \mathrm{pmp})$, and the number of organs recovered from one donor was 3.58 (Fig. 1). The number of organs donated per donor by age group was 4.94 in teens, 4.98 in their $20 \mathrm{~s}, 4.28$ in their $30 \mathrm{~s}$, but less than 3.0 in the over 60s (Fig. 2 ). The number of organs that were recovered but not transplanted and discarded was 12 out of 1,630 , accounting for $0.7 \%$.

Among the potential brain deaths notified to Korea Organ Donation Agency (KODA), 15.1\% wished to stop life-sustaining treatment, and their organ donation consent rate was $10.9 \%$ of the family contacted group. This is much lower than the $37.4 \%$ of the patient group who did not wish to discontinue life-sustaining treatment; therefore, special attention is needed for the family approach to the group wishing to discontinue life-sustaining treatment in the future (Table 1) [1]. When looking at the entire donation process, the proportion of patients who consented to organ donation among medically eligible patients decreased every year to $33.0 \%$ in 2019 (Table 2). The reasons for the decline in consent rate are that people think their appearance becomes ugly and disgusting after the donation process and that the donor family

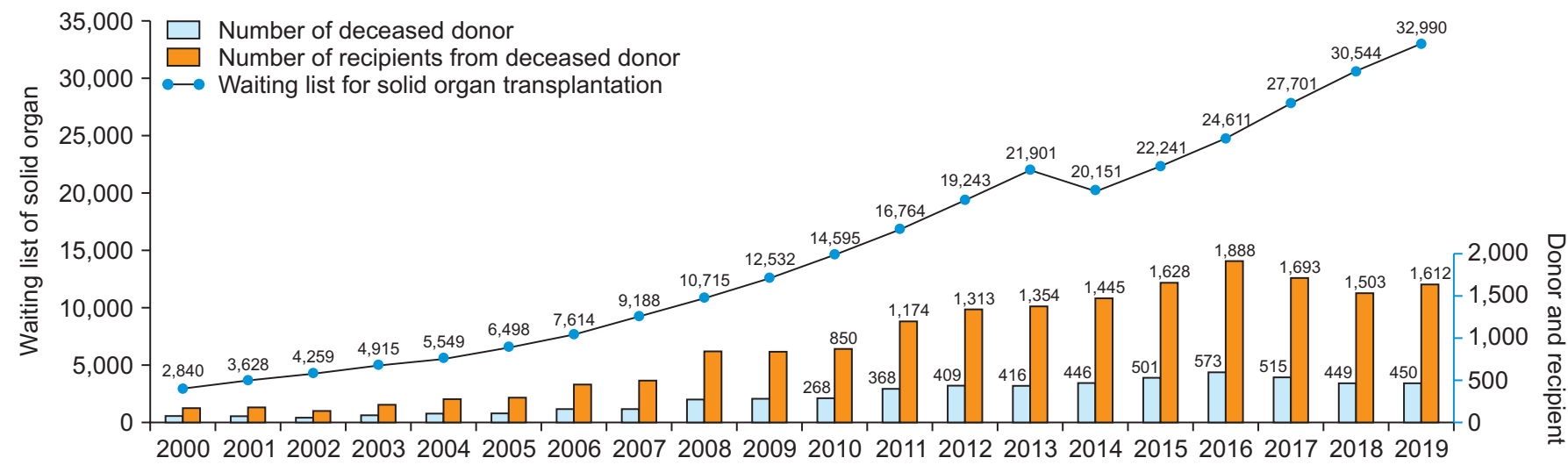

Fig. 1. Annual number of deceased donors and recipients from deceased donors. Important indicators of deceased donor in 2019: donor age, 66 day-86 yr (average, $47.0 \mathrm{yr}$ ); donor sex ratio (M:F), 2:1; brain death donor per million population, 8.70; number of recovered organs per donor, 3.58; recovered but not transplanted organs, 0.7\%. Data from Korea Organ Donation Agency annual report 2019 [1].

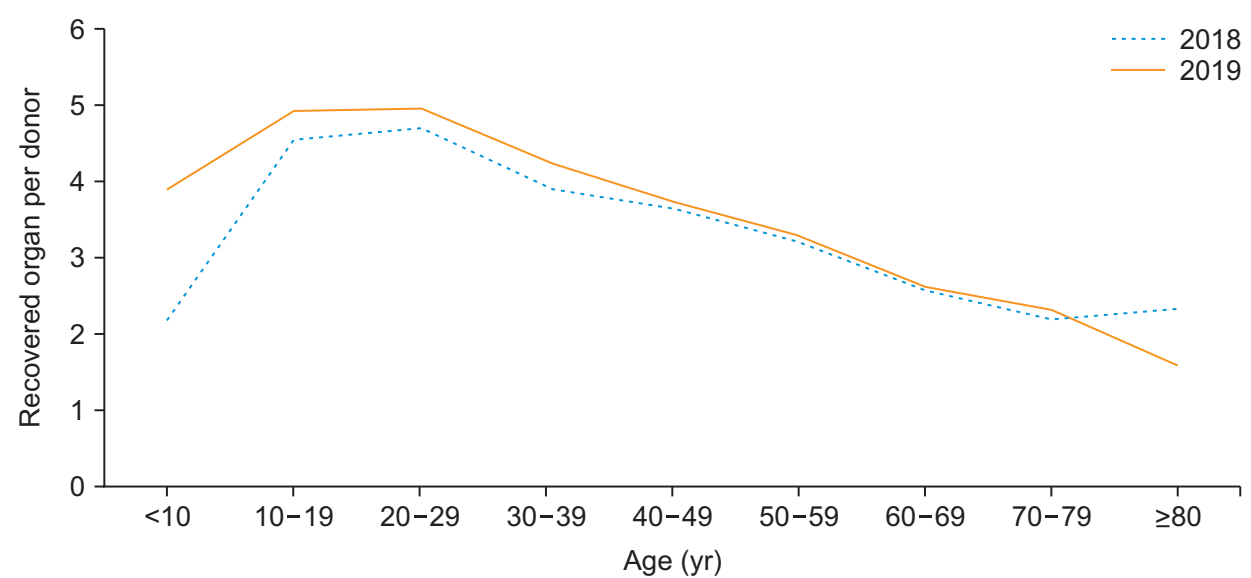

Fig. 2. Recovered organs per deceased donor by age group in 2019. Data from Korea Organ Donation Agency annual report 2019 [1]. 
wants to avoid the brain death examination and donation procedure which takes a long time compared to stopping life-sustaining treatment.

The causes of brain death were cerebrovascular disease in $38.4 \%$ of cases, hypoxic brain injury due to cardiovascular disease or hanging in $32.2 \%$ of cases, and traffic accident or traumatic brain injury in $28.2 \%$ of cases (Fig. 3 ). From 2018, the number of donor management at the hospitals that signed a brain death management agree- ment with KODA outpacing that of hospitals named HOPO (Hospital-Based Organ Procurement Organization; 54.2\% vs. $45.8 \%$ in 2019) (Fig. 4) [1].

\section{STAGE OF BRAIN DEATH DONOR MANAGEMENT}

The domestic brain death donor management stage be-

Table 1. Consent rate according to the intention about life-sustaining treatment

\begin{tabular}{|c|c|c|c|c|}
\hline Total reported case & \multicolumn{2}{|c|}{ Intention of life-sustaining treatment } & $\begin{array}{c}\text { Medically suitable \& } \\
\text { family approached (/intention } \\
\text { about life-sustaining) }\end{array}$ & $\begin{array}{c}\text { Agree donation } \\
\text { (/medically suitable \& } \\
\text { family approached) }\end{array}$ \\
\hline \multirow[t]{2}{*}{2,484} & Want & 376 & $267(71.0)$ & $29(10.9)$ \\
\hline & Do not want & 2,108 & $1,339(63.5)$ & $501(37.4)$ \\
\hline
\end{tabular}

Values are presented as number (\%).

Data from Korea Organ Donation Agency annual report 2019 [1].

Table 2. Result of potential brain death donor reported to KODA (2015-2019)

\begin{tabular}{cccccc}
\hline Year & $\begin{array}{c}\text { PBD reported to } \\
\text { KODA referral center }\end{array}$ & $\begin{array}{c}\text { Medically } \\
\text { suitable PBD }\end{array}$ & $\begin{array}{c}\text { PBD possible to } \\
\text { family interview }{ }^{\text {b) }}\end{array}$ & $\begin{array}{c}\text { Agreed to organ donation } \\
\text { (consent rate) }{ }^{\mathrm{c})}\end{array}$ & $\begin{array}{c}\text { Procure rate (more than } \\
\text { one organ procured) })^{\text {d) }}\end{array}$ \\
\hline 2015 & 1,850 & $1,344(72.6)$ & $1,068(79.5)$ & $552(51.7)$ & $501(46.9)$ \\
2016 & 2,083 & $1,538(73.8)$ & $1,237(80.4)$ & $652(52.7)$ & $573(46.3)$ \\
2017 & 2,216 & $1,692(76.4)$ & $1,348(79.7)$ & $578(42.9)$ & $515(38.2)$ \\
2018 & 2,426 & $1,833(75.6)$ & $1,393(75.9)$ & $509(36.5)$ & $449(32.2)$ \\
2019 & 2,484 & $2,009(80.8)$ & $1,606(79.9)$ & $530(33.0)$ & $450(28.0)$ \\
\hline
\end{tabular}

Values are presented as number (\%).

KODA, Korea Organ Donation Agency; PBD, potential brain death.

${ }^{\text {a) }}$ Medical suitable/report to KODA; ${ }^{\text {b) }}$ Family interview/medical suitable; ${ }^{c)}$ Consent/family interview; ${ }^{\text {d) }}$ Procure/family interview.

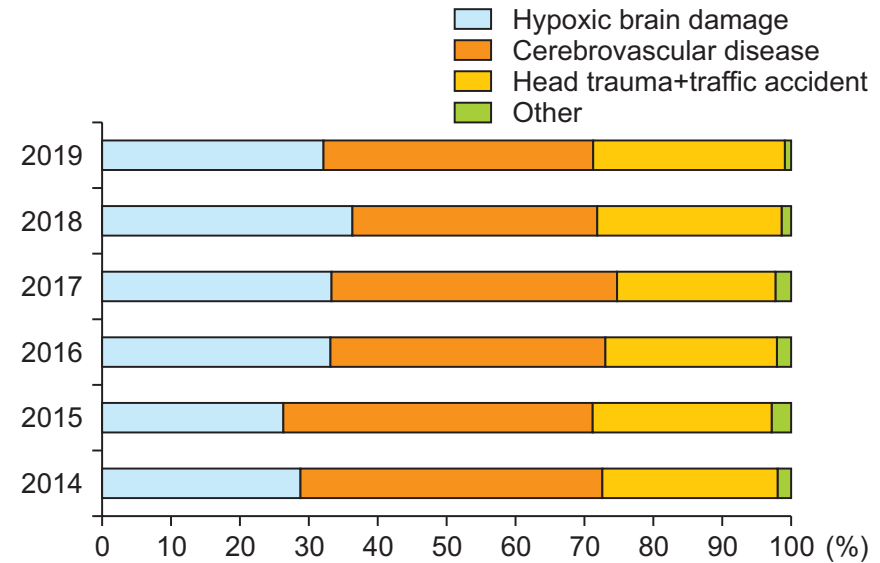

Fig. 3. Change of causes of brain death in 2019. Data from Korea Organ Donation Agency annual report 2019 [1].

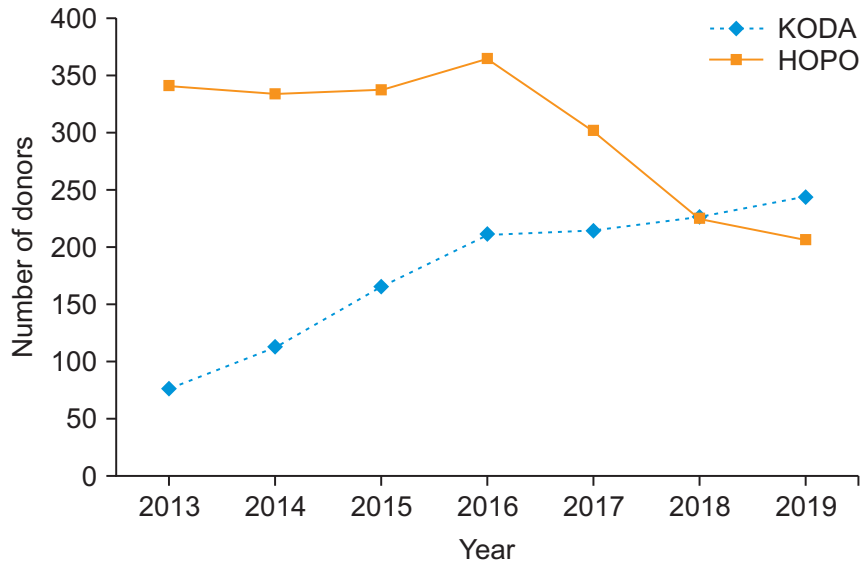

Fig. 4. Number of donors managed by Korea Organ Donation Agency (KODA) and Hospital-Based Organ Procurement Organization (HOPO) [1]. 
gins when a family requests a brain death judgment on the premise of organ donation in accordance with the Act on Organ Transplantation. Unusually, according to the domestic law, a brain-dead patient is not recognized as dead unless an organ donation is made. In Western countries, death determined on the basis of neurological criteria (brain death) is legally recognized as death, so when the attending physician explains to the patient's family that the patient is in a state of brain death, the family will recognize that the patient is in a state of death. Because of this unclear legal definition of death in the domestic act of organ transplantation, a brain dead family may doubt whether its family member has died or not. Other problems that raise legal ambiguity are developed when the patient dies during the process of brain death judgment or when the patient decides to stop life-sustaining measures and wishes to donate organs. Because of the unclear definition of death in the current domestic transplant act, the process of donation after circulatory death may be delayed, and cannot be performed under current domestic law.

Considering that efforts to resolve the shortage of donated organs are being emphasized globally, efforts for self-sufficiency of organs should be continued in Korea, not only at the level of the people but the government by revising the law and system. The donation process of brain dead organ donors can be divided into the following six stages (Fig. 5). (1) Stages to identify suspected brain death and link to donor information center of KODA. (2) Stage for evaluation of medical suitability for organ donation. (3) Stage to approach the family and get a family's agreement about organ donation. (4) Stage for brain death investigation, management, and holding brain death committee. (5) Stage to enter the operating theater and organ recovery. (6) Stage for repairing the body and handing over the deceased body to the family.

\section{ANALYSIS OF THE CAUSES OF DROPOUT AT EACH STAGE UNTIL FINISHING ORGAN RECOVERY}

\section{Analysis of the Time Required to Recover Organ after Reporting to KODA Information Center}

The time required for each management stage was re-divided into the following six steps for easy analysis (Fig. 5). Step 1: from notification to the end of the first brain death investigation (stage 1-3). Step 2: from the end of the first investigation to the end of the second investigation (stage 4). Step 3: from the end of the second investigation until the flat electroencephalogram (EEG) confirmation (stage 4). Step 4: until the end of the brain death committee after flat brain wave (stage 4). Step 5: from the end of the brain death committee to the entrance to the operating room (stage 5). Step 6: after entering the operating room until the end of organ recovery and body handover to the family (stage 5,6 ).

It usually takes about 4.18 days from dispatching the KODA coordinator to the donor hospital until finishing the organ recovery. However, there are many variables in this period depending on the patient's situation, family cooperation, and the presence of medical staff. Fig. 5 shows the average time interval taken for each management step of potential brain death over the past 3 years. According to the law, after the first brain death investigation, the second investigation can be conducted at intervals of 6 hours. However, in the field, it took an average of 11.5 hours, nearly twice as long. Another 5.3 hours were required to obtain a flat EEG after the second brain death investigation. Forty-five persons died during this period. After all brain death investigations are completed, another 5.9 hours were taken for the brain death committee, which is unnecessary for the Western organ donation system. In order to enter the operating room, 6.6 hours were required after the completion of the brain death committee, but this is necessary for the adjustment between the recovery teams, the preparation of the operating room for emergency organ recovery surgery, and for the recipient preparation.

The average time to enter the operating room after the first brain death examination was 29.3 hours, but some of the cases took 2-3 days (48 hours in 119 cases, 71.1 hours in 63 cases). From the perspective of the family, it is harsh for them to wait for such a long time even after deciding to donate organs. Sometimes they regret the decision just because it takes a long time. From the coordinator's point of view, it already took an average of 67.4 hours (2.8 days) to complete the first brain death investigation from receiving notification, so the shortening of the whole process is urgent to improve the quality of donated organs and to reduce the number of mortalities.

\section{Stage to Discover Suspected Brain Death and Link to KODA Information Center}

Analysis of the causes of dropout

Of the 2,484 potential brain deaths reported to KODA, only 


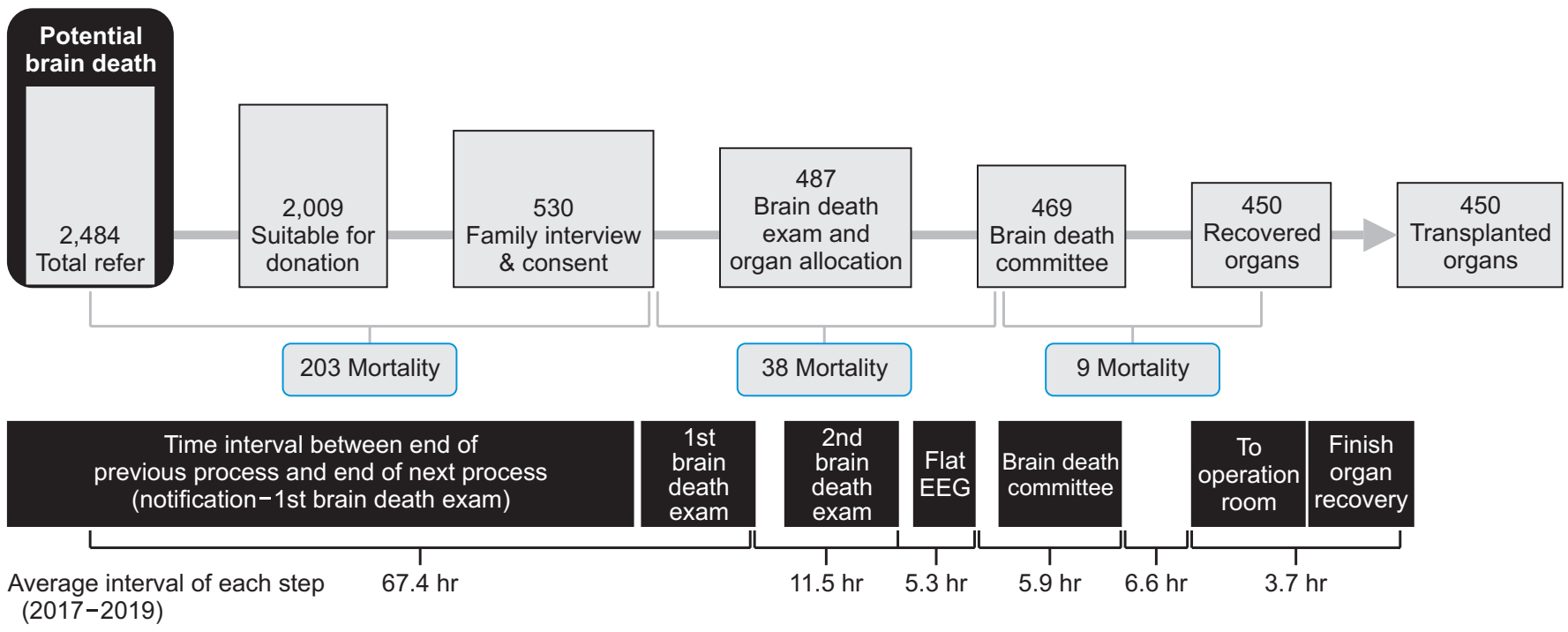

Fig. 5. Donation process of brain-dead organ donors and time spent on each step. EEG, electroencephalogram. Data from Korea Organ Donation Agency annual report 2019 [1].

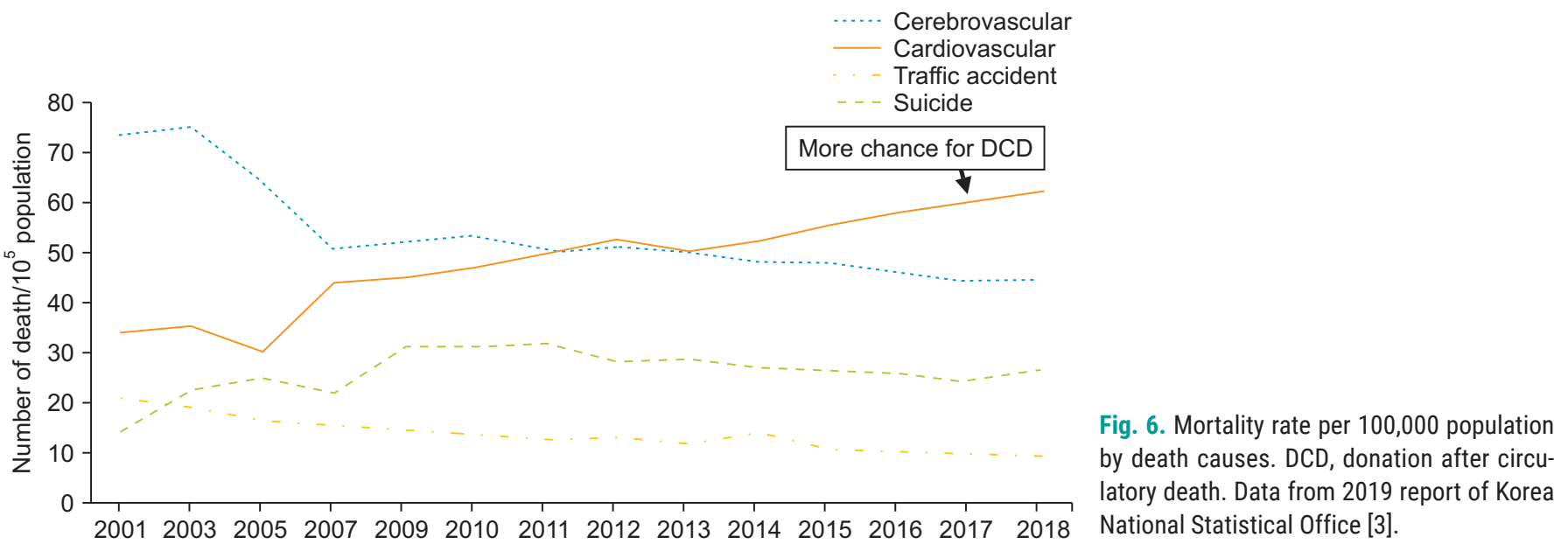

$18.1 \%(n=450)$ were ultimately successful in organ donation. Some patients were medically unsuitable to donate, while others were not brain-dead. There are also patients who decided to stop life-sustaining treatment and cannot lead to organ donation. Unfortunately, there are no accurate statistics on how many brain deaths occurred in Korea. However, the Organ Procurement and Transplantation Network (OPTN) study from the United States reported that about $1.5 \%$ of total annual death ( $4.6 \%$ of inpatient) were estimated potential donors and among them, $21.3 \%$ were actual deceased donors [2]. If we calculate potential brain death in Korea at the same rate, it will be 4,500 (total numbers of death in Korea are around 300,000 ) and actu- al deceased donor will be about 959 cases. If we can get an average of 3.5 organs from each donor, 3,357 organs can be obtained arithmetically. However, even if we follow this hypothesis, we still suffer the lack of organs for transplantation. We need more solutions for organ shortage, and Western countries partly solved organ shortage by expanding the organ source into the donation after circulatory death. In the International Registry on Organ Donation and Transplantation (IRODaT) report, more than $10 \%-40 \%$ of deceased donor organ transplantations were from donation after circulatory death [4]. According to a 2016 meta-analysis reported by Sandroni et al [5], about $10 \%$ of the 23,388 adult deaths by cardiac arrest showed 
brain death, especially in the group of patients who underwent extracorporeal cardiopulmonary resuscitation rather than classic cardiopulmonary resuscitation. In addition, it was reported that $40 \%$ of patients who became brain-dead after cardiopulmonary resuscitation due to cardiac arrest donated organs. Therefore, it is argued that patients with hypoxic brain injury without return of consciousness despite resuscitation after cardiac arrest (especially those who have undergone extracorporeal cardiopulmonary resuscitation) should be given an opportunity to donate organs by conducting an investigation on brain death before the decision to remove the life support device.

According to a report by the Korea National Statistical Office, 62 patients per 100,000 people died from cardiovascular diseases in 2018 and the number increased continuously during the last 10 years [3]. We can expect more brain deaths caused by ischemic brain injury secondary to cardiac arrest. Therefore, paying attention to manage the secondary hypoxic brain injury patients due to cardiac arrest should be emphasized to increase deceased organ donors (Fig. 6).

When comparing the number of brain deaths reported to KODA (pmp) and the actual management of brain deaths of each local government, there is a correlation between the two. Local governments that reported more notifications than the national average (solid line in Fig. 7) had more actual donors (dotted line in the Fig. 7) than the other regional governments.

Spaces that can be improved

\section{Required reporting system}

The current provisions for reporting suspected brain death are legally mandatory, but brain death is determined by the

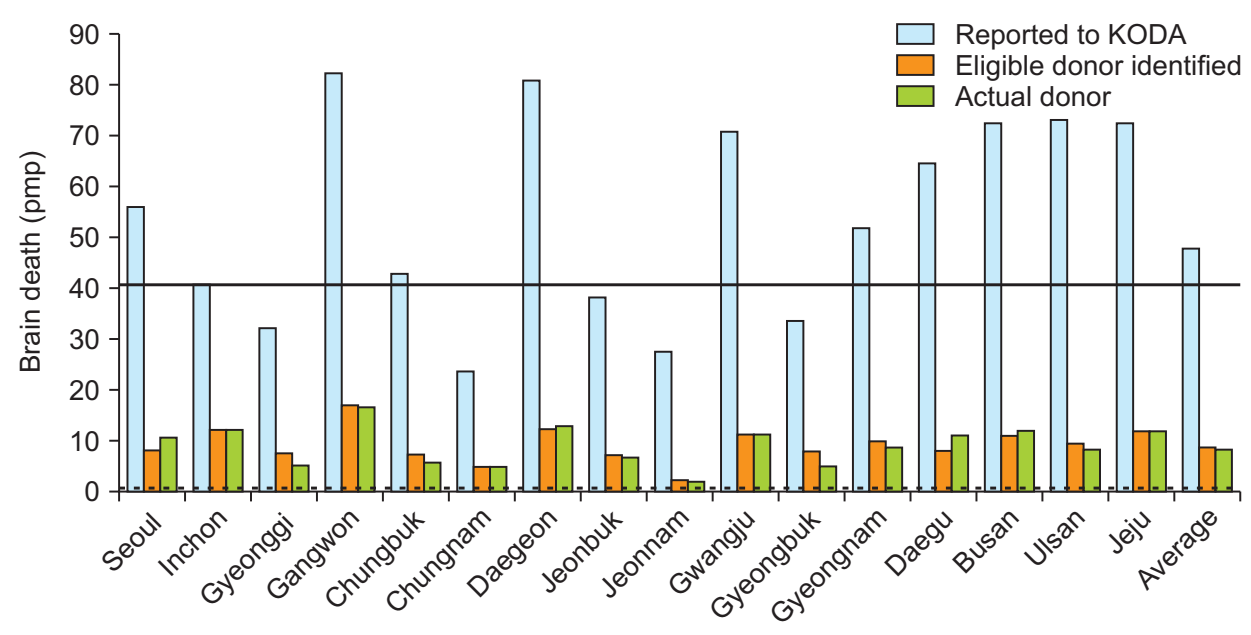

Fig. 7. Potential brain death reported to Korea Organ Donation Agency and actual organ donor per million population (pmp) of each local government. Data from Korea Organ Donation Agency annual report 2019 [1].

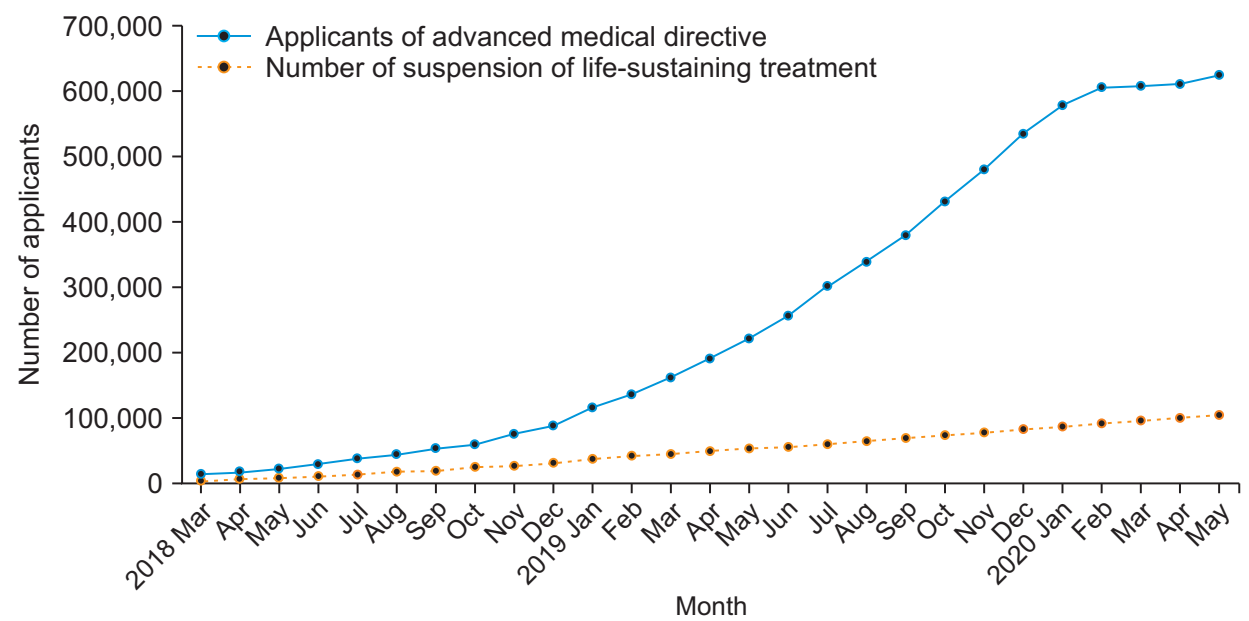

Fig. 8. Cumulative number of applicants for advanced medical directives and actual suspension of life-sustaining treatment. Data from National Agency for Management of Life-Sustaining Treatment [6]. 
attending physician in accordance with the enforcement regulations, so it is difficult to contact all the potential brain death cases without regular audits of the hospital deaths by a medical record review. As in Western countries, if all imminent deaths are linked, an organ donation coordinator can be dispatched to confirm the suitability of donation, the patient's life-time intention about donation, and prior medical instructions for discontinuation of life-sustaining treatment; the donation process can then be continued. By doing this, we can contact more potential brain death cases and can reduce the chance of family members dying without an opportunity to be explained about organ donation.

Prepare for rapid increase of advanced medical directives Since the registration of advance medical directives is increasing rapidly, reaching 600,000 people 2 years after the enforcement of the law, it is necessary to confirm their usual intentions whether they only want to stop life-sustaining treatment or they want organ donation to other people as well (Fig. 8) [6]. The donation intention of patients who wish to donate organs and tissue at the same time, should be respected, and everyone should try to accomplish this. In order to successfully implement this system, we need a guideline and specialists to classify and care for the end of life patient. However, all of these procedures should not be in conflict with the dead donor rule (Fig. 9) [7].

\section{Active cooperation of local governments in promoting}

organ donation

If each local government and affiliated medical institutions are more interested in life-sharing and activating organ donation to local residents, the reporting of potential brain deaths will increase along with the number of actual donors. Therefore, we believe that local governments should actively participate in life sharing. In order to alleviate the transportation problems of harvested organs due to the recent increase in traffic volume and to achieve a balanced development of transplant medicine in cities across the country, local governments should try to spread the spirit of life-sharing and activate organ transplants from brain deaths.

\section{Stage for Evaluation of Donation Eligibility}

Analysis of the cause of dropout

Of the referred patients, 475 (19.1\%) were eliminated from the donation suitability assessment, of which 240 did not meet the prerequisites for brain death and 235 were medically unsuitable for donation. The criteria for reporting potential brain death (Article 11 of the Enforcement Rule of the Act on Transplantation of Organs) include those who are unconscious with irreversible brain injury, equipped with a ventilator because of no spontaneous breathing, and patients missing five or more brain stem reflex. However, the ability to determine brain death in advance is not easy. Therefore, KODA has an education program (donor improvement program [DIP]) for each hospital so as to have an ability to detect potential brain death at an early stage, and to report them immediately.

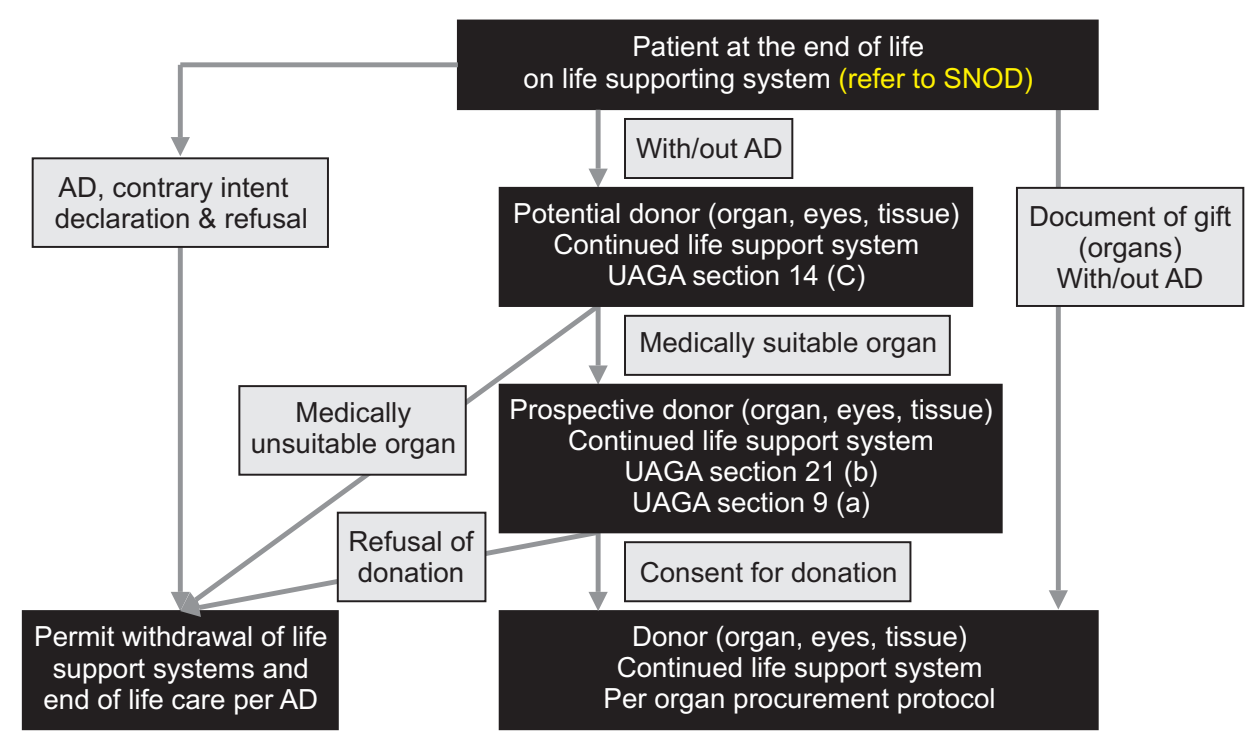

Fig. 9. Protocol to manage end of life patients. Revised Uniform Anatomical Gift Act (UAGA). AD, advance health care directive; SNOD, specialist nurse in organ donation. Modified from Verheijde et al. [7]. 
In addition, medically, patients with cancer or systemic infections have to be discriminated from donation targets. In the case of metabolic coma, carbon monoxide poisoning, shock or hypothermia, some cases are reversible, so it should be excluded at the beginning of the brain death determination process. If there is an injury to the organs to be donated, the patient should be excluded before we proceed to brain death evaluation. All of these are basic requirements for brain death evaluation, but many mis-judgements or confusions might develop when the medical staff in charge is changed. It is also true that when the medical staff changes, it takes time to get used to the job such as understanding, managing, and reporting brain death. Establishing a close relationship between new medical staff and the KODA coordinator is another practical problem.

Spaces that can be improved

Continuous training of employees on the concept of brain death and attitudes toward organ donation

During the hospital attitude survey, we asked about the level of knowledge on brain death, and the recognition rate when a brain death occurs in the hospital. The medical staff who had been continuously educated by KODA for more than 5 years showed a higher brain death recognition rate compared to other hospitals' staff ( $75.5 \%$ vs. $68.4 \%)$ [1]. This result means that the implementation of DIP is effective in improving the knowledge and recognition rate of brain death. In addition, the eligible rate for organ donation among the reported potential brain death increased from $72.6 \%$ in 2015 to $80.9 \%$ in 2019 . This suggests that even though the medical staff changed, the DIP for education and establishing relationships from scratch has to be repeated [8].

\section{Stage for Family Interview}

Analysis of the causes of dropout

Even if the coordinator determines that the notified brain death patient is suitable for donation, it is often not possible to interview the guardian under actual circumstances. Only through interviews can the patient's family be explained the condition of brain death, and consultations on organ donation be conducted, but this opportunity is not provided at all if coordinator cannot see the family. For various reasons, the medical staff in charge or medical institutions refused to interview the parents (163 patients). Many patients died (203 patients) during the delay of the interview (Fig. 5) [1]. It is important to keep in mind that a patient with brain death is in very vulnerable status with no idea when the heart will stop.

Spaces that can be improved

Report all potential donor to KODA information center The decision of the doctor in charge about the impossibility of organ donation due to various causes or problems in the treatment process should be respected. However, the doctor on duty can apply a "decoupling" technique in conversation about introducing the organ donation to the family. By using a decoupling procedure, we can separate the attending physician who explains the result of treatment, and organ procurement coordinator who explains and counsels about organ donation. If this separation works successfully, the attending physician can reduce the burden of telling family members to donate organs since the patient is no longer likely to recover, and this also can get a higher consent rate for organ donation if requested by specialized coordinator $[8,9]$.

\section{Required request before give up life}

Another possible process to give donation information to every family of brain dead patients is "required request" system. When a patient becomes brain dead, the attending physician must ask his or her family about the intention to donate.

\section{Active implementation of the $D C D$ system}

Many deaths occur at this stage, but some of them can donate organs through DCD. Since brain deaths are unstable hemodynamically, preparation for DCD such as an emergency organ harvesting team and resuscitation team is necessary in each hospital. The current law is controversial, but only the prompt implementation of the DCD system for organ donation after cardiac arrest can increase donation opportunities from vulnerable brain dead donors $[10,11]$. In particular, organ donation during the brain death judgment process (Maastricht category IV) or in patients with interrupting life-sustaining treatment (Maastricht category III) is possible only with a public consensus about timing of declaration of death and the readiness of each medical institution for joining the urgent organ procurement process. In fact, since each transplant center in Korea has already experienced organ recovery from numerous brain death patients, organ donation from patients after circulatory arrest is not considered a major technical problem. If a patient dies due to circulatory arrest but is not diagnosed as brain dead (Maastricht category II), organ donation may be possible after cardio-pulmonary 


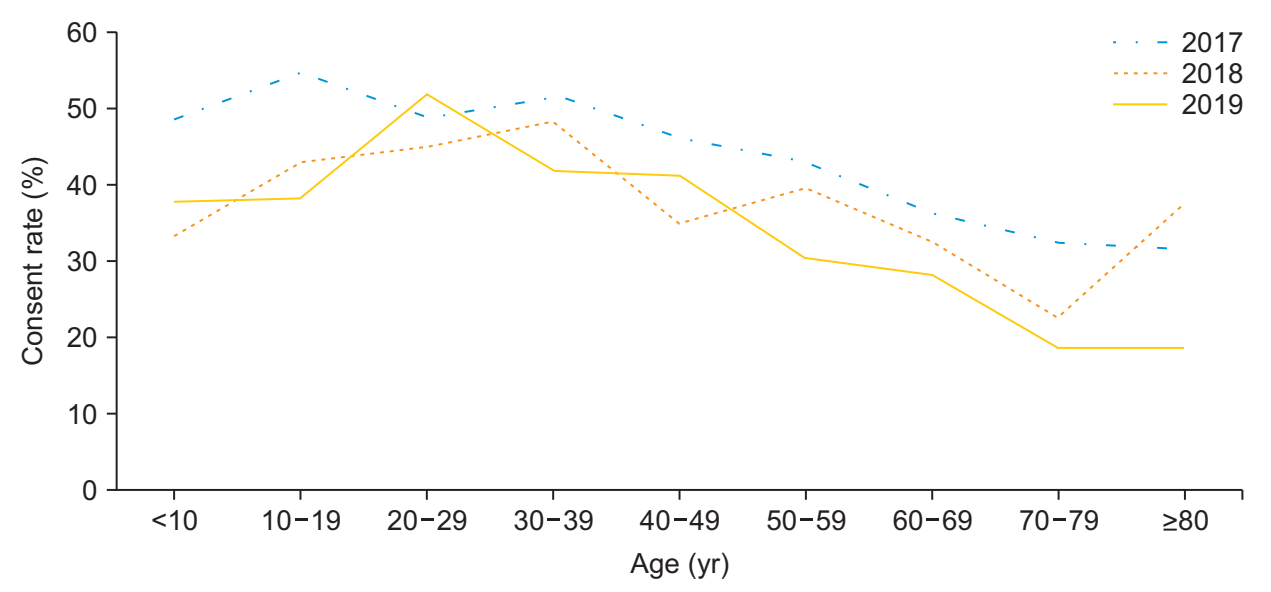

Fig. 10. Consent rate by age group of deceased donors. Data from Korea Organ Donation Agency annual report 2019 [1]. resuscitation, depending on the preparation of medical staff and medical institutions. However, at the beginning of $D C D$, activation of the emergency organ procurement system for category 3 or 4 should be prepared first.

Close relationship with the family of potential brain death Some families who refuse to be interviewed by a KODA coordinator despite the doctor's recommendation need special strategies to allow natural contact with the coordinator.

\section{Stage of Receiving Donation Consent}

Analysis of the cause of dropout

Of the 1,606 patients who were able to contact with family for consultation about organ donation, 764 had already revealed their intention to refuse before the interview with KODA coordinator, and 312 had refused even after hearing the explanation from the coordinator. It is regrettable that the 764 in the initial refusal group had no opportunity to be explained by a KODA coordinator [1].

Looking at the donation consent rate by age group (Fig. 10), the rate in the $20 \mathrm{~s}, 30 \mathrm{~s}$, and 40 s were $52.1 \%$, $41.9 \%$, and $41.3 \%$, respectively; whereas those in the 50 s, 60 s, and 70 s were, respectively, $30.5 \%, 28.3 \%$, and $18.6 \%$. Most donors at younger ages are suitable for donation because their organs function well. However, organs of older donors tend to be avoided by many transplant medical staff as they are often degraded. To avoid making this decision by prejudice, it is necessary to analyze whether the rejection is because the physiologic function of these organs or general condition of these donors. Some of the attending physicians decide in advance that the organ or condition of the aged group is unsuitable for donation and have a tendency to not report it to KODA.
Space that can be improved

For more consent from family interview

The decoupling of the explanation of the treatment process and the donation option can increase the family's consent rate and can alleviate a lot of burden on the attending physician as well [8].

Education, publicity, and priority of government policy on life sharing

The consent rate of families who heard about organ donation of their loved one is closely related to the national consensus on life sharing, education and publicity and government policies to save terminally ill patients using all possible donor resources. Nationwide efforts are needed to solve these problems.

\section{Respect the usual intention of deceased-First Person Authorization}

In particular, all family members, medical staff, and citizens must work together to ensure that the brain dead who registered for donation should succeed in organ donation as they intended. The intention of applicants for organ donation registration may be ignored by family during the consent process. To prevent this from happening, many countries have implemented the First Person Authorization Act $[12,13]$, and in order to ensure the success of this law, it is recommended to notify and consult with family members when registering organ donation $[9,14]$. In addition, in Korea, where the number of applicants for organ donation is only about $3 \%$ of the total population, a national campaign to increase the number of registered applicants for organ and tissue is needed.

Life sharing is a part of dying well at the last moment 
Recently, interest in 'well-dying' is increasing, so it may be helpful to explain that life-sharing will give their deceased a "well-dying" at the last moment.

Never give up the aged donor

In order to have active transplant from an expanded category donor, especially organs from aged donors, it is necessary to readjust the organ allocation principle, improve the physiological function of the donated organ, and use a mechanical perfusion method to maintain and improve the recovered organs.

\section{Revision of the transplant law about concept of death} Under the Korean transplant law, brain death is recognized as death only when an organ donation is agreed by the family of a potential brain death. Because of this, families might be suspicious about death of their loved one and hesitate to agree about organ donation when they first hear about organ donation from the attending physician. Therefore, it is an urgent need to revise the provisions of the law to indicate that brain death is dead.

\section{Stage for Brain Death Examination, Judgment, and Management after Consent}

Analysis of the cause of dropout

The average time taken from the first brain death test to finishing the brain death committee was 22.7 hours, and 47 out of 530 patients with final consent died during this stage (Fig. 5). This stage includes a waiting time to get a flat EEG and a preparation of the brain death committee. In terms of respecting the will of the patient who consented to donation, the number of deaths occurring during this period should be minimized. The problem is that in the current domestic organ transplant law, even if the first and second brain death tests and confirmation tests are conducted by two different medical professionals at designated times, the results must be referred to the brain death committee for final judgment. The legal time of death is the time when the brain death committee ended, and after that, organ donation surgery can be performed. Most of the patients are in a very unstable state because they have already gone through 1-3 days of examination and management. Delay in time may lead to cardiac arrest of brain dead patients, but in Korea, it is mandatory to go through the brain death committee.

Space that can be improved

Prepare emergency organ recovery (DCD)
If cardiac arrest developed during this period, emergency organ recovery might be performed if resuscitation does not work. However, this is only possible when we have a well-trained emergency recovery team within the hospital.

\section{About brain death committee}

The number of mortalities in this period can be reduced if we shorten the time spent for this process. Especially for brain death committee which is not conducted in Western countries, we can save several hours in the future, if committee's decision might be replaced by two brain death examinations.

Preparation for shortage of medical personnel

We need an experienced medical staff to manage the brain-dead patient until we can get a result of the committee not only during the week days but also during weekends and holidays. As an alternative, it is necessary to give a prescription to KODA's coordinator to take care of brain dead patients, especially during the night or holidays when medical personnel are not available at the right time.

\section{Stages of Organ Recovery and Repair of the Thoraco- Abdominal Wall}

Analysis of the cause of dropout

In some cases, we have to give up the organ recovery because of unexpected quality of organs, especially the liver. Severe fatty liver or cirrhosis might be unsuitable for transplantation. To evaluate liver status, liver biopsy is usually done before surgeons proceed to tissue dissection. Unexpectedly detected malignancy which was not recognized before exploration of abdomen is also a cause of dropout at this stage. Sometimes, the organs to be harvested are damaged due to an accident that caused brain death. Marked atherosclerosis of the feeding artery of recovered organs that is impossible to reconstruct on the back-table is another cause of dropout.

If an essential tissue such as feeding artery, vein, ureter or bile duct is amputated during organ recovery, that donor surgeon must notify this fact to the recipient surgeon in order to prepare an emergency situation in advance. Severe arteriosclerosis of blood vessels were not found during the donor evaluation, anatomical abnormalities, thrombosis in the organs due to insufficient perfusion (malpositioning of perfusion tube, inexperienced perfusion techniques), air embolism, unexpected malignancy, etc. should be reported to the recipient surgery team. Some of them can be repaired and successfully transplanted but others may 
be discarded even though we made tremendous efforts. In cases of prolonged time of donor management, physiologic function of some organs may be deteriorated and cannot be used.

Space that can be improved

All donor teams should follow adjusted time schedule

Surgery may be delayed because the operating room for emergency donation surgery is not always available. In addition, sometimes, the donor surgery team assigned to each organ may be delayed due to various circumstances of their own hospital. However this is not something that can be understood as an excuse. The scheduled operation time notified by coordinator must be strictly followed by everyone. The last stage of the organ harvest request is a very skillful surgery, requiring a shorter time in order to save the organ's function and quality. Shortening the time for organ recovery surgery can alleviate the pain of families who have already waited for a long time outside the operating room.

Again, a DCD system should be prepared

If unexpected cardiac arrest developed during this stage, emergency organ recovery under the guideline of Maastricht category IV will be possible [10].

\section{Experienced evaluation of the surgical field prior to dissection of organs}

Biopsy of small size tumor masses detected after exploring abdominal cavity may done to confirm their nature and severity. If the result of biopsy turns out as a malignancy, all recipient teams should be notified about result and decide whether they will continue transplantation or discard that organ. However, if we can eliminate unexpected events before we precede to donor surgery, that will be best.

\section{Specialized organ recovery team in organ procurement organization}

If the recovery team of recipient hospital is not ready, we can ask a local procure team instead and transport the organs after recovery. In order to prevent postponement of organ recovery due to the absence of medical staff on holidays and weekends, surgeons specializing in organ recovery may be run by organ procurement organizations.

Need for a skillful experienced donor surgeon and to always communicate with surgeons of other recipient hospitals
The medical staff responsible for organ harvesting should be a surgeon with considerable experience, and in the case of tissue dissection and harvesting, the extent of the resection margin (especially artery and vein) should be discussed and determined so as not to interfere with the use of other organs. The serious problem is that the kidneys, which are harvested last after all of the liver, pancreas, and small intestine have already been recovered. During organ harvesting, unintended surgical accidents such as ligation of the arterial branch or polar artery, amputation of large arteries, and resection of the ureter can occur. If this is not recognized by the harvesting team, and not reported to the recipient team, they will be very embarrassed while doing the recipient surgery, and sometimes they may have to give up the transplant. In order to prevent this, anatomical abnormalities or blood vessel damage that occurred during organ recovery should be sufficiently reconstructed before transplantation and transplant surgeon should have that kind of ability.

Need for a better qualified recovery team and donor surgeon

To improve the capabilities and quality of the surgical team, each transplant center and transplant society should make regular and continuous efforts to educate the donor team not only on surgical skill but also with regards to attitude and ethics. The donor surgeon license system and renewal at regular intervals is one way to challenge the capable competent donor surgeon.

\section{CONCLUSIONS}

Two important sources of deceased organ donors are donation after brain death and donation after circulatory death. The basic concept of organ donation from a deceased person is to respect the donor's usual will or family intentions to make the donation successful. To achieve this goal, ongoing efforts must be made to convert reported potential brain deaths into real donors. As a result of reviewing the records of brain death over the past few years, the following suggestions are made to activate brain death donation.

First, all suspected brain deaths occurring in Korea should be linked to the KODA information center. Second, an opportunity to donate organs should be provided to those who want to discontinue life-sustaining treatment 
and had received prior medical directives. Third, since the number of brain death donors shows a great difference between each local government, encourage local governments to strongly activate organ donation. Fourth, to reduce mortality during brain death management, unnecessary time during the management process should be reduced. Finally, we need to work together to build a DCD system that can harvest organs from circulatory death.

\section{ACKNOWLEDGMENTS}

\section{Conflict of Interest}

No potential conflict of interest relevant to this article was reported.

\section{Funding/Support}

This study was supported by research grant from the Korean Society for Transplantation (2020-00-02001-004).

\section{ORCID}

Won-Hyun Cho https://orcid.org/0000-0001-5916-6601

\section{REFERENCES}

1. Korea Organ Donation Agency. KODA annual report 2019. Seoul: Korea Organ Donation Agency; 2019.

2. Klassen DK, Edwards LB, Stewart DE, Glazier AK, Orlowski JP, Berg CL. The OPTN deceased donor potential study: implications for policy and practice. Am J Transplant 2016;16:1707-14.

3. Statistics Korea. Changes in death rates by major causes of death from report on the causes of death statistics 2019. Daejeon: Statistics Korea; 2019.

4. International registry in organ donation and transplantation. Preliminary numbers 2018: IRODat international registry in organ donation and transplantation [Internet]. Barcelona: International registry in organ donation and transplantation [cited 2020 Oct 20].
Available from: www.irodat.org.

5. Sandroni C, D'Arrigo S, Callaway CW, Cariou A, Dragancea I, Taccone FS, et al. The rate of brain death and organ donation in patients resuscitated from cardiac arrest: a systematic review and meta-analysis. Intensive Care Med 2016;42:1661-71.

6. National Agency for Management of Life-Sustaining Treatment website [Internet]. Seoul: National Agency for Management of Life-Sustaining Treatment; 2002 [cited 2020 Dec 5]. Available from: https://www.lst. go.kr.

7. Verheijde JL, Rady MY, McGregor JL. The United States Revised Uniform Anatomical Gift Act (2006): New challenges to balancing patient rights and physician responsibilities. Philos Ethics Humanit Med 2007;2:19.

8. Siminoff LA, Gordon N, Hewlett J, Arnold RM. Factors influencing families' consent for donation of solid organs for transplantation. JAMA 2001;286:71-7.

9. Haliko S, Arnold R. Fast facts and concepts \#79: discussing organ donation with families [Internet]. Palliative Care Network of Wisconsin; 2002 [cited 2020 Oct 10]. Available from: https://www.mypcnow.org/fastfact/discussing-organ-donation-with-families/.

10. Shemie SD, Baker AJ, Knoll G, Wall W, Rocker G, Howes $D$, et al. National recommendations for donation after cardiocirculatory death in Canada: donation after cardiocirculatory death in Canada. CMAJ 2006;175:S1.

11. Bernat JL, D'Alessandro AM, Port FK, Bleck TP, Heard SO, Medina J, et al. Report of a National Conference on Donation after cardiac death. Am J Transplant 2006;6:281-91.

12. Sokohl K. First person consent: OPOs across the country are adapting to the change. UNOS Update 2002:1, 3.

13. Callison K, Levin A. Donor registries, first-person consent legislation, and the supply of deceased organ donors. J Health Econ 2016;49:70-5.

14. Blood and Transplant. Tell your family and friends: take time to talk about organ donation [Internet]. Bristol: Blood and Transplant; 2020 [cited 2020 Oct 10]. Available from: www.organdonation.nhs.uk/. 